\title{
Profil kondisi fisik atlet bola voli remaja wanita
}

\section{Profile of the physical condition of female adolescent volleyball athletes}

\author{
Titi Harianti ${ }^{*}$, Sukardi2, Farizal Imansyah ${ }^{1}$ \\ ${ }^{1}$ Pendidikan Jasmani, FKIP, Universitas PGRI Palembang, Palembang, Indonesia \\ ${ }^{2}$ Pendidikan Sejarah, FKIP, Universitas PGRI Palembang, Palembang, Indonesia \\ *Corresponding Author
}

\begin{abstract}
Abstrak
Tujuan penelitian ini adalah untuk mengetahui tingkat kondisi fisik pemain bola voli remaja yang berada di SMP Negeri 01 Kisam Tinggi. Jenis penelitian ini adalah penelitian deskriptif kualitatif dengan sampel penelitian berjumlah 12 atlet pemain bola voli putri remaja. Komponen kondisi fisik yang diukur dalam penelitian ini adalah daya tahan aerobik, daya tahan kekuatan otot lengan, kecepatan, daya ledak otot tungkai, dan kelincahan. Instrumen dalam penelitian ini menggunakan Tes Kebugaran Jasmani Indonesia Usia 13-15 Tahun. Hasil penelitian menunjukkan bahwa kondisi fisik atlet bola voli wanita pada usia rema di SMP Negeri 01 Kisam Tinggi dikategorikan dalam kategori sedang. Dari hasil penelitian tersebut maka diperlukan metode Latihan yang cocok dengan memperhatikan karakteristik sampel penelitian untuk meningkatkan kondisi fisik atlet bola voli remaja wanita.
\end{abstract}

Kata Kunci: kondisi fisik; bola voli; remaja; wanita.

\begin{abstract}
The purpose of this study was to determine the level of physical condition of adolescent volleyball players in SMP Negeri 01 Kisam Tinggi. This type of research is a qualitative descriptive study with a research sample of 12 teenage female volleyball players. The components of physical condition measured in this study were aerobic endurance, arm muscle strength endurance, speed, leg muscle explosive power, and agility. The instrument in this study used the Indonesian Physical Fitness Test for 13-15 Years Old. The results showed that the physical condition of female volleyball athletes in their teens at SMP Negeri 01 Kisam Tinggi was categorized in the moderate category. From the results of these studies, it is necessary to use a suitable exercise method by taking into account the characteristics of the research sample to improve the physical condition of female adolescent volleyball athletes.
\end{abstract}

Keywords: physical condition; volleyball; adolescent; female.

Received: 9 Oktober 2021; Revised: 12 October 2021; Accepted: 17 October 2021

Corresponding author: Titi Harianti, JL. Jend. A. Yani Lrg. Gotong Royong

Palembang

Email: hariantititi@gmail.com

\section{PENDAHULUAN}

Pendidikan adalah usaha sadar dan terencana untuk mewujudkan suasana belajar dan proses pembelajaran agar peserta didik secara aktif 
Titi Harianti, Sukardi, Farizal Imansyah

mengembangkan potensi dirinya untuk memiliki kekuatan spiritual keagamaan, pengendalian diri kepribadian, kecerdasan, akhlak mulia, serta keterampilan yang diperlukan dirinya, masyarakat, Bangsa dan Negara (Husdarta \& Saputra, 2013). Salah satu program pendidikan nasional yang diberikan pada setiap satuan pendidikan adalah pendidik jasmani. Pendidikan jasmani dan olahraga (penjasor) adalah proses pendidikan melalui aktivitas jasmani dan olahraga yang terpilih untuk mencapai tujuan pendidikan (Bayu \& Andrianto, 2014; Mashuri et al., 2019). Dari pengertian ini, menunjukkan bahwa pendidikan jasmani dan olahraga merupakan bagian tak terpisahkan dari pendidikan umum. Tujuannya adalah untuk membantu anak agar tumbuh dan berkembang secara wajar sesuai dengan tujuan pendidikan nasional, yaitu menjadi manusia indonesia seutuhnya.

Ginanjar, (2019) berpendapat bahawa pencapaian tujuan tersebut berpangkal pada perencanaan pengalaman gerak yang sesuai dengan karakteristik peserta didik. Olahraga merupakan kegiatan yang dibutuhkan oleh setiap orang, dengan berolahraga yang teratur seseorang akan mendapatkan kesegaran jasmani kesegaran pemikirannya sehingga dapat meningkatkan produktif kerja. Dalam Undang-Undang Republik Indonesia No. 3 Tahun 2005 tentang sistem keolahragan nasional pasal 4 berbunyi keolahragaan nasional bertujuan untuk memelihara dan meningkatkan kesehatan dan kebugaran prestasi, kualitas manusia menanamkan nilai norma dan akhlak yang mulia, sportifitas dan disiplin, mempererat dan membina persatuan dan kesatuan bangsa (Undang-Undang Republik Indonesia Nomor 3 Tahun 2005 Tentang Sistem Keolahragaan Nasional Dengan, 2005).

Pengembangan olahraga prestasi dapat dilakukan melalui satuan pendidikan yang dapat menerapkan dalam program ekstrakurikuler. Ekstrakurikuler merupakan bagian dari pendidikan yang mewadahi bakat dan minat peserta didik dalam bidang tertentu. Jenis ekstrakurikuler yang dapat dilaksanakan adalah olahraga, salah satunya cabang olahraga bola voli. Permainan bola voli adalah permainan olahraga yang dimainkan oleh dua grup berlawanan. Masing-masing grup memiliki enam orang pemain dan area permainannya dipisahlan oleh net (Kusumawati, 2015). 
Untuk dapat meningkatkan prestasi atau peforma olahraga tidak hanya didapatkan dengan program latihan fisik, teknik, dan taktik saja (Hidayatullah, 2019), tetapi atlet perlu memiliki mental yang kuat dan tangguh (Sabilla \& Jannah, 2017). Karena dalam pertandingan, penentu kemenangan tidak hanya faktor fisik dan strategi, tetapi faktor mental juga dapat menentukan kemenangan sebuah tim. Dalam penelitian ini, fokus pertama adalah mengetahui kondisi fisik terlebih dulu sebelum kita menerapkan program latihan fisik, teknik, taktik, dan mental.

\section{METODE}

Penelitian ini dilakukan di SMP Negeri 1 Kisam Tinggi Kecamatan Kisam Tinggi Kabupaten Oku Selatan, waktu penelitian dilaksanakan mulai dari bulan Desember 2020 sampai dengan bulan Februari 2021. Jenis penelitian ini adalah penelitian bersifat deskriptif dan kuantitatif, penelitian dengan memperoleh data yang berbentuk angka atau data kuantitatif yang diangkakan (Arikunto, 2013). Populasi penelitian ini adalah seluruh pemain bola voli SMP Negeri 1 Kisam Tinggi yang berjumlah 12 orang atlet pemain bola voli. Data penelitian ini adalah data hasil dari Tes Kebugaran Jasmani Indonesia (TKJI) Usia 13-15 Tahun, yang terdiri dari lari cepat 50 meter, gantung siku tekuk, baring duduk (sit-up) 60 detik, loncat tegak (vertical jump), dan lari cepat 100 meter. Nilai yang diperoleh tes yang sudah dilaksanakan dijumlahkan kemudian hasil dari penjumlahan akan menjadi dasar untuk menentukan kategori tingkat kondisi fisik atlet bola voli dengan menggunakan norma TKJI Usia 13-15 Tahun untuk perempuan. Data yang diperoleh dari penelitian ini akan dianalisis dengan menggunakan teknik deskriptif kuantitatif yang data diperoleh akan diolah dan diklasifikasikan.

\section{HASIL}

Hasil pengukuran dengan lima jenis tes pengukuran yang meliputi tes lari cepat 50 meter, tes angkat tubuh, tes baring duduk (60detik), tes loncat tegak, dan tes lari cepat 100 meter. Deskripsi hasil penelitian masingmasing tes tersebut diuraikan sebagai berikut.

Tabel 1. Hasil kategorisasi TKJI

Kategori Lari Cepat Angkat Baring Loncat Lari Cepat




\begin{tabular}{cccccc}
\hline & 50 meter & Tubuh & Duduk & Tegak & 100 meter \\
\hline Baik Sekali & 0 & 0 & 0 & 0 & 0 \\
Baik & 1 & 5 & 0 & 3 & 0 \\
Sedang & 3 & 4 & 5 & 3 & 9 \\
Kurang & 4 & 3 & 3 & 3 & 3 \\
Kurang Sekali & 0 & 0 & 4 & 3 & 0 \\
\hline Jumlah & $\mathbf{1 2}$ & $\mathbf{1 2}$ & $\mathbf{1 2}$ & $\mathbf{1 2}$ & $\mathbf{1 2}$ \\
\hline
\end{tabular}

Tes lari cepat 50 meter berdasarkan tabel 1 menunjukkan bahwah terdapat 5 orang $(20 \%)$ atlet pemain bola voli putri SMP Negeri 1 Kisam Tinggi menunjukan kata gori baik, 3 orang atlet (64\%) termasuk klasfikasi sedang, dan 5 orang atlet (16\%) termasuk klasfikasi kurang. Sehingga ratarata kemampuan lari 50 meter menunjukan nilai sedang.

Tes angkat tubuh menunjukkan bahwa terdapat 5 atlet $(33,34 \%)$ menunjukkan kategori baik, 4 atlet $(22,22 \%)$ termasuk kategori sedang, dan 3 atlet $(44,44 \%)$ termasuk kategori kurang. Sehingga kemampuan angkat tubuh menunjukan nilai rata-rata kurang. Tes baring duduk selama 60 detik menunjukkan bahwa 5 atlet $(38,46 \%)$ termasuk kategori sedang dan 3 atlet $(25 \%)$ termasuk kategori kurang, 4 atlet $(33,33 \%)$ termasuk klasfikasi kurang sekali. Tes Baring duduk/puul up 60 detik menunjukan nila ratarata sedang.

Tes loncat tegak menunjukkan bahawa terdapat 3 atlet (25\%) pada kategori baik, 3 atlet (25\%) menunjukan kategori sedang, 3 atlet (25\%) menunjukaan kategori kurang, dan 3 atlet (25\%) menunjukan kategori kurang sekali. Sehingga kemampuan loncat tegak menunjukan nilai ratarata sedang. Tes Lari 100meter menunjukkan terdapat 9 atlet $(75 \%)$ termasuk dalam kategori sedang, dan 3 atelt (25\%) termasuk dalam kategori kurang. Sehingga kemampuan lari 100 meter menunjukkan nilai rata-rata sedang.

\section{PEMBAHASAN}

Komponen kondisi fisik sangat dibutuhkan untuk mendukung penguasaan ketrampilan teknik dan taktik dalam suatu cabang olahraga khususnya permainan bola voli. Karena pada prinsipnya latihan sangat mempengaruhi kondisi fisik yang berkaitan dengan pola pembinaan, peningkatan serta pencapaian prestasi yang optimal, latihan yang dimaksud 
adalah latihan fisik yang harus ditata, direncanakan, dan dilakukan dengan baik dan sistematis sehingga bisa meningkatkan kemampuan biomotorik yang dibutuhkan (Bompa \& Buzzichelli, 2019). Beberapa komponen fisik yang perlu dikembangkan adalah: 1) kelentukan berguna untuk mengurangi rasa sakit pada saat berolahraga ketika melakukan latihan kondisi fisik (Musumeci, 2015); 2) kecepatan gerak atau dikenal bentuk Speed-AgilityQuicknes (SAQ) berguna untuk mengetahui peningkatan kecepatan gerak dan kelincahan untuk menjaga anda mengendalikan gerakan tubuh dengan cepat, dan lebih efisien tanpa harus kehilangan keseimbangan (Subekti et al., 2021); 3) kekuatan (strengh) Kemampuan yang sangat erat hubungannya dengan adanya proses kontraksi otot. Berguna untuk meningkatkan metabolism dan menjaga fungsi organ tubuh (Mashuda \& Purnomo, 2013); dan 4) daya tahan merupakan kemampuan organisme tubuh untuk mengatasi kelelahan yang disebabkan oleh pembebanan yang berlangsung relatif lama (Ziv \& Lidor, 2011).

Dalam memberikan latihan fisik tekanan harus banyak diberikan pada perkembangan tubuh secara teratur dan seksama, intensitasnya bisa ditingkatkan. Proses ini harus dilakukan dengan ketelatenan dan kewaspadaan, dengan kondisi fisik yang baik maka: 1) ada peningkatan dalam kemampuan sistem sirkulasi dan kerja kelenturan; 2) ada peningkatan dalam komponen kondisi fisik; 3) ada gerak yang lebih baik pada waktu latihan; 4) ada waktu pemulihan yang lebih cepat dalam organorgan tubuh setelah latihan; dan 5) ada respon yang cepat dari organisme tubuh (Bafirman \& Wahyuri, 2019). Dari hasil penelitian tersebut pola pembinaan latihan kondisi fisik dan teknik di SMP Negeri 01 Kisam Tinggi perlu ditingkatkan, sebab kondisi fisik anggota pemain bola voli putri SMP Negeri 01 Kisam Tinggi dalam kategori sedang. Kondisi fisik mempunyai peranan yang penting dan pada prinsipnya latihan sangat mempengaruhi kondisi fisik yang berkaitan pola pembinaan, peningkatan serta pencapaian prestasi yang maksimal, khususnya pembinaan prestasi olahraga bola voli. Sehingga dari latihan yang teratur dan terorganisir tersebut kondisi fisik dapat meningkatkan menjadi baik atau baik sekali. 


\section{KESIMPULAN}

Berdasarkan hasil penelitian dan pembahasan dapat diambil simpulan bahwah Tingkat kondisi fisik pemain bola voli putri SMP Negeri 01 Kisam Tinggi kondisi fisiknya termasuk dalam kategori sedang. Dengan adanya data primer seperti ini, maka pelatih dan atau pembina ekstrakurikuler olahraga bola voli harus memberikan porsi latihan fisik yang sesuai dengan kondisi atlet untuk dapat meningkatkan kondisi fisik atlet, sehingga prestasi juga akan dapat dicapai.

\section{KONTRIBUSI PENULIS}

Author 1: Writing; Review \& Editing. Author 2: Methodology; Validating. Author 3: Software and Writing; Original Draft.

\section{DAFTAR PUSTAKA}

Arikunto, S. (2013). Prosedur Penelitian: Suatu Pendekatan Praktik. Rineka Cipta.

Bafirman, \& Wahyuri, A. S. (2019). Pembentukan Kondisi Fisik. Rajawali Pers.

Bayu, W. I., \& Andrianto, J. R. (2014). Profil Pendidikan Jasmani, Olahraga, Dan Kesehatan Pada Tingkat Satuan Pendidikan Sekolah Menengah Atas Se-Kabupaten Jombang Tahun 2016. Bravo's Jurnal, 2(3), 89-97. https://ejournal.stkipjb.ac.id/index.php/penjas/article/view/442/330

Bompa, T. O., \& Buzzichelli, C. (2019). Periodization: Theory and Methodology of Training (6th ed.). Human Kinetics.

Ginanjar, A. (2019). Implementasi Praktis Sport Education Model. Program Studi Pendidikan Jasmani, Kesehatan, dan Rekreasi, STKIP Nahdatul Ulama Indramayu.

Hidayatullah, F. (2019). Pemetaan kompetensi pengetahuan pembina dan pelatih ekstrakurikuler bola basket di tingkat sekolah menengah kabupaten Bangkalan. Multilateral Jurnal Pendidikan Jasmani Dan Olahraga, 17(2), 67-76. https://doi.org/ 10.20527/multilateral.v17i2.5703

Husdarta, J. S., \& Saputra, Y. M. (2013). Belajar dan Pembelajaran Pendidikan Jasmani dan Kesehatan. Alfabeta.

Kusumawati, M. (2015). Penelitian Pendidikan Penjasorkes. Alfabeta.

Mashuda, I., \& Purnomo, M. (2013). Kontribusi konsentrasi, kekuatan otot lengan, kekuatan otot kaki, kelentukan punggung terhadap pukulan ke arah outfield olahraga softball. Jurnal Prestasi Olahraga, 1(1), 1-8. https: / / www.neliti.com/id/publications / 247169/

Mashuri, H., Puspitasari, I. C., \& Abadi, S. M. (2019). Pendidikan Jasmani 
Titi Harianti, Sukardi, Farizal Imansyah

dan Olahraga: Sebuah Pandangan Filosofi. Prosiding SEMDIKJAR (Seminar Nasional Pendidikan Dan Pembelajaran), 3, 383-390. http://ojs.semdikjar.fkip.unpkediri.ac.id/index.php/SEMDIKJAR/articl e/view/41

Musumeci, G. (2015). Effects of exercise on physical limitations and fatigue in rheumatic diseases. World Journal of Orthopaedics, 6(10), 762-769. https://doi.org/10.5312/wjo.v6.i10.762

Sabilla, J. I., \& Jannah, M. (2017). Intimasi Pelatih-Atlet dan Kecemasan Bertanding Pada Atlet Bola Voli Putri. Jurnal Psikologi Teori Dan Terapan, 7(2), 123. https://doi.org/10.26740/jptt.v7n2.p123-129

Subekti, N., Syaukani, A. A., Fatoni, M., Subroto, S., \& Raihan, A. A. D. A. (2021). Exercise Speed, Agility and Quickness (SAQ) To Improve Physical Fitness. Kinestetik: Jurnal Mmiah Pendidikan Jasmani, 5(1), 95-101. https://doi.org/10.33369/jk.v5i1.14359

Undang-Undang Republik Indonesia Nomor 3 Tahun 2005 Tentang Sistem Keolahragaan Nasional Dengan, Pub. L. No. 3, Presiden RI 1 (2005). https://www.dpr.go.id/dokjdih/document/uu/45.pdf

Ziv, G., \& Lidor, R. (2011). Physical characteristics, physiological attributes, and on-field performances of soccer goalkeepers. International Journal of Sports Physiology and Performance, 6(4), 509-524. https:/ / doi.org/ 10.1123/ijspp.6.4.509 